\title{
Estratégias de combate à dengue através da educação em saúde: uma revisão integrativa
}

\author{
Ivanise Brito da Silva1, Danielli Gavião Mallmann², Eliane Maria Ribeiro de Vasconcelos ${ }^{3}$
}

\begin{abstract}
RESUMO
Este estudo objetivou analisar, na literatura, quais estratégias de educação em saúde estão sendo utilizadas para controle/combate da dengue no Brasil. Trata-se de uma revisão integrativa realizada nas bases de dados MEDLINE e LILACS e bibliotecas SCIELO e COCHRANE, por meio do cruzamento dos descritores Dengue e Educação em Saúde. Encontraram-se cinco publicações, das quais emergiram duas categorias temáticas: Modelos e estratégias usados na educação em saúde e Problemas identificados no processo de educação em saúde. Os programas de combate a dengue apresentam um modelo de educação verticalizada, tradicional, centrada no emissor, que utiliza estratégias pouco atrativas, havendo necessidade de mudanças nas práticas de educação vigentes, substituindo-as por uma forma que promova a participação comunitária. Os artigos apresentaram como solução para as falhas da educação em saúde o desenvolvimento de estratégias que priorizem a participação popular e que promovam um cuidado integral.
\end{abstract}

Descritores: Dengue; Educação em Saúde; Saúde Pública.

\section{Strategies to combat dengue through health education: an integrative review}

\begin{abstract}
This study aimed to analyze, in the literature, what health education strategies are being used to control / combat dengue in Brazil. This is an integrative review developed in databases MEDLINE and LILACS and libraries SciELO and Cochrane, through crossing descriptors Dengue and Health Education. It was found five publications, of which emerged two thematic categories: Models and strategies used in health education and Problems identified in the process of health education. Programs to combat dengue present a model of verticalized, traditional, centered on the transmitter education, which uses unattractive strategies, with the need for changes in current education practices, replacing them with a way that promotes community participation. The articles presented as solution to the failures of the health education the development of strategies that prioritize popular participation and promote integral care.
\end{abstract}

Descriptors: Dengue; Health Education; Public Health.

${ }^{1}$ Enfermeira pela Universidade Federal de Pernambuco (UFPE), Recife, PE, Brasil.

${ }^{2}$ Mestre em Enfermagem pela Universidade Federal de Pernambuco (UFPE), Recife, PE, Brasil.

${ }^{3}$ Doutora em Enfermagem pela Universidade Federal de Santa Catarina (UFSC), Florianópolis, SC, Brasil. 


\section{Introdução}

O termo doenças tropicais é usado para conceituar as doenças mais presentes na região dos trópicos e que estão intimamente relacionadas com as variáveis climáticas e as condições políticas, econômicas e socioambientais. Nesse âmbito, a dengue é considerada uma doença tropical, pois as condições climáticas dessas regiões facilitam a manutenção do mosquito responsável pela sua transmissão".

A dengue é uma arbovirose, cujo agente etiológico é um vírus do gênero Flavivírus pertencente à família Flaviviridae, transmitida pela picada do mosquito infectado ${ }^{2}$. Duas espécies de mosquitos podem transmitir a dengue: o Aedes aegypti e - Aedes albopictus. Contudo, no Brasil, há registros de transmissão da dengue apenas pelo Aedes aegypti, que é, também, responsável pela transmissão da febre amarela, uma vez que o Aedes albopictus não apresenta característica domiciliar' ${ }^{1}$.

A transmissão da dengue acontece através da picada da fêmea do Aedes aegypti, no ciclo homem - Aedes aegypti homem. 0 mosquito torna-se apto a transmitir o vírus depois de 8 a 12 dias de incubação, após um repasto de sangue infectado. Ressalta-se que não há transmissão por contato direto com o doente ou com suas secreções².

A enfermidade apresenta duas formas clínicas: Dengue Clássica ou Febre da Dengue (FD) e Febre Hemorrágica da Dengue (FHD). A FD apresenta quadro clínico caracterizado por febre associada à cefaleia, vômitos e dores no corpo $^{3}$. A FHD apresenta, inicialmente, sintomas clínicos parecidos com a FD, porém estes evoluem rapidamente para manifestações hemorrágicas como: febre alta, fenômenos hemorrágicos, hepatomegalia e insuficiência circulatória, bem como trombocitopenia. Nestes casos, a principal característica fisiopatológica associada ao grau de severidade da FHD é a efusão do plasma, que se manifesta através de valores crescentes do hematócrito e da hemoconcentração 4 .

Há, ainda, uma forma clínica "atípica" que resulta no comprometimento intenso de um órgão ou sistema específico, gerando encefalopatias, miocardiopatia, hepatopatia, insuficiência renal aguda e outras também associadas à mortalidade 3 .

A dengue está ligada a condições socioambientais que promovem a manutenção e dispersão do vetor ${ }^{5}$. 0 mosquito transmissor se reproduz em locais onde há água parada como, por exemplo, pneus, depósitos de ferros velhos descobertos, latas, garrafas, plásticos abandonados e terrenos baldios. A eliminação do mosquito deverá acontecer através da eliminação dos criadouros, uso de inseticida, principalmente durante a época de transmissão, e apoio da população 6 .

Considerando a importância da doença e suas consequências para a saúde da população, o governo tem investido em políticas públicas de combate à dengue, por exemplo, o Programa Nacional de Controle da Dengue (PNCD), implantado em 2002, o qual propõe mudanças na forma de controlar a doença, enfatizando a importância da adesão e mobilização social, bem como incentiva a atuação das pessoas como "sanitaristas" responsáveis pelo controle de potenciais criadouros ${ }^{4}$.

Com essa forma de enfrentamento, a educação em saúde ganha destaque, substituindo as práticas meramente campanhistas. Em contrapartida, para obtenção de êxito, são necessárias mudanças nas práticas de educação e comunicação, pois as práticas de comunicação e educação realizadas para o controle da dengue caracterizam-se pelo modelo hegemônico centralizado, vertical e unidirecional, orientadas através da difusão de conhecimentos, objetivando mudanças de hábitos e comportamentos da população?.

A educação em saúde hegemônica pouco tem atuado na promoção da saúde, em contrapartida a concepção freireana, tipo de educação que valoriza o saber do outro e entende o conhecimento como um processo de construção coletiva, torna-se essencial na participação ativa da população e promoção da educação sanitária ${ }^{8}$. Acredita-se que o combate da epidemia da dengue no Brasil pode ser enfrentado com um trabalho horizontal, onde a educação em saúde é uma das estratégias que poderá ter êxito.

Desta forma, ao sensibilizar-se com a elevada incidência da doença, propõem-se investigar quais as estratégias de educação em saúde estão sendo utilizadas para controle/combate da dengue no Brasil.

\section{Metodologia}

Trata-se de pesquisa bibliográfica, do tipo revisão integrativa, método que promove a síntese dos resultados de pesquisas ${ }^{9}$. Este estudo foi composto por seis etapas: identificação do tema ou questionamento da revisão integrativa; amostragem ou busca na literatura; categorização dos estudos; avaliação dos estudos incluídos na revisão; interpretação dos resultados e síntese do conhecimento evidenciado nos artigos analisados ou apresentação da revisão integrativa ${ }^{10}$.

O estudo ocorreu nos meses de março e abril de 2013, tendo como questão de pesquisa: Quais as evidências científicas sobre como estão sendo trabalhadas as estratégias de Educação em Saúde no controle/combate da dengue no Brasil? 
A coleta de artigos foi realizada nas bases de dados: Medical Literature Analysis and Retrieval System Online (MEDLINE), Literatura Latino-Americana e do Caribe em Ciências da Saúde (LILACS), Biblioteca Cochrane (COCHRANE) e na Biblioteca Virtual Scientific Eletronic Library Online (SCIELO), utilizando-se como descritores de assunto "Dengue" e "Educação em saúde", bem como suas respectivas traduções nos idiomas inglês e espanhol. Para a busca, foi utilizado o booleano "and".

Como critérios de inclusão, tiveram-se artigos científicos brasileiros, indexados no período de 2008-2012, escritos nos idiomas inglês, português ou espanhol e que estivessem disponibilizados online. Como critérios de exclusão teve-se publicações no formato teses, dissertações, capítulos de livro, as que não tinham relação com o tema da pesquisa, bem como as que tratavam de estudos sobre dengue realizados fora do Brasil.

Obteve-se como resultado 136 artigos, dos quais somente cinco estavam de acordo com os critérios de inclusão deste estudo. Os motivos de exclusão dos artigos estão expostos na tabela 1.

Tabela 1 - Distribuição da exclusão dos artigos encontrados nas bases de dados pesquisadas de acordo com os motivos de exclusão

\begin{tabular}{c|c|c|c|c|c}
\hline Motivo de exclusão & LILACS & MEDLINE & COCHRANE & SCIELO & Total \\
\hline Outro ano & 21 & 18 & 01 & 01 & 41 \\
\hline $\begin{array}{c}\text { Estudo realizado em outro país } \\
\begin{array}{c}\text { Resumo insuficiente, não atendendo ao } \\
\text { objetivo deste estudo }\end{array}\end{array}$ & 06 & 07 & 01 & 00 & 14 \\
\hline Total excluído & 52 & 29 & 01 & 11 & 66 \\
\hline Total incluído & 05 & 05 & 00 & 05 & 05 \\
\hline
\end{tabular}

A análise dos cinco artigos selecionados foi realizada com um instrumento, previamente validado ${ }^{11}$, que apresenta: amostra do estudo (sujeitos), objetivos, metodologia empregada, resultados e principais conclusões de cada estudo.

Realizou-se um fichamento das publicações selecionadas, objetivando identificar as diferentes experiências utilizadas na tentativa de combate/controle da dengue. Fizeram-se leituras críticas, com o objetivo de responder a questão condutora. Dessas leituras, obteve-se categorização temática de acordo com conteúdos encontrados nas publicações.

\section{Resultados}

Os resultados serão apresentados, a seguir, por meio da Tabela 2, que mostra as publicações que compuseram a amostra do estudo e as variáveis analisadas para melhor clarificação dos resultados encontrados. Os artigos selecionados foram todos estudos do tipo qualitativo, sendo três trabalhos de campo, uma revisão de literatura e um relato de experiência.

Quanto aos objetivos propostos pelas publicações, identificou-se que dois artigos abordavam as dificuldades enfrentadas nas práticas de educação em saúde, um investigou o tipo de comunicação usada na prevenção da doença, outro, a necessidade de integração entre ensino-serviço-comunidade e, por fim, um investigou o uso da linguagem teatral como estratégia de educação em saúde.

As pesquisas foram realizadas por diversos profissionais da área da saúde, entre os quais estão: enfermeiro, médicos, bacharel em ciências sociais, assistente social e acadêmicos de enfermagem e de medicina. Essa diversidade entre as áreas de atuação dos autores confere, ao tema, uma necessidade de olhar multidisciplinar, porém revela que, apesar da preocupação de diferentes profissionais, o tema não é trabalhado frequentemente, visto o número pequeno de publicações encontradas, bem como o intervalo de anos entre uma e outra.

Ao analisar os artigos, observou-se a relação dos mesmos à questão norteadora do estudo, dos quais emergiram duas categorias: 1) Modelos e estratégias usadas na educação em saúde, 2) Problemas e soluções identificados no processo de educação em saúde. 
Tabela 2 - Distribuição da amostra do estudo quanto as variáveis: título, autores, ano de publicação e objetivo

\begin{tabular}{|c|c|c|}
\hline Título & Autores / Ano & Objetivo \\
\hline $\begin{array}{l}\text { Ações de educação em saúde para } \\
\text { prevenção e controle da dengue: um } \\
\text { estudo em Icaraí, Caucaia, Ceará }\end{array}$ & $\begin{array}{l}\text { Sales FMS. } \\
\qquad 2008\end{array}$ & $\begin{array}{l}\text { Analisar as ações educativas para } \\
\text { prevenção e controle da dengue, } \\
\text { as estratégias utilizadas nas ações } \\
\text { educativas e apontar os limites/ } \\
\text { dificuldades. }\end{array}$ \\
\hline $\begin{array}{c}\text { Dengue: educação, comunicação e } \\
\text { mobilização na perspectiva do controle - } \\
\text { propostas inovadoras }\end{array}$ & $\begin{array}{l}\text { Rangel ML. } \\
2008\end{array}$ & $\begin{array}{l}\text { Colocar em evidência alguns problemas } \\
\text { relativos às práticas de educação, } \\
\text { comunicação e mobilização comunitárias } \\
\text { no controle da dengue. }\end{array}$ \\
\hline $\begin{array}{c}\text { Comunicação sazonal sobre a dengue } \\
\text { em grupos socioeducativos na atenção } \\
\text { primária à saúde }\end{array}$ & $\begin{array}{c}\text { Silva LB, } \\
\text { Soares S, } \\
\text { Fernandes, MTO, } \\
\text { Aquino AL. } \\
2011\end{array}$ & $\begin{array}{c}\text { Analisar como se estabelece a } \\
\text { comunicação sazonal nos grupos } \\
\text { socioeducativos de equipes de Saúde } \\
\text { da Família para prevenção e controle da } \\
\text { dengue. }\end{array}$ \\
\hline $\begin{array}{l}\text { PET-Saúde: uma Experiência Prática de } \\
\text { Integração Ensino-serviço-comunidade }\end{array}$ & $\begin{array}{l}\text { Ferreira VS, Barreto RLM, Oliveira EK, } \\
\text { Ferreira PRF, Santos LPS, Marques VEA, } \\
\text { et al. } \\
2012\end{array}$ & $\begin{array}{l}\text { Apresentar a experiência de integração } \\
\text { entre ensino-serviço-comunidade } \\
\text { vivenciada durante o desenvolvimento do } \\
\text { projeto de mobilização contra a dengue. }\end{array}$ \\
\hline $\begin{array}{l}\text { Construção de espaços de escuta, } \\
\text { diagnóstico e análise coletiva de } \\
\text { problemas de saúde pública com a } \\
\text { linguagem teatral: o caso das oficinas de } \\
\text { jogos teatrais sobre a dengue }\end{array}$ & $\begin{array}{l}\text { Oliveira DF, Mendonça CCR, Meirelles } \\
\text { RMS, Coutinho CMLM, Araújo-Jorge TC, } \\
\text { Luz MRMP. } \\
2012\end{array}$ & $\begin{array}{l}\text { Investigar a utilização da linguagem } \\
\text { teatral como estratégia para caracterizar } \\
\text { as concepções de educadores envolvidos } \\
\text { na prevenção da dengue, por meio de } \\
\text { Oficinas de Jogos Teatrais. }\end{array}$ \\
\hline
\end{tabular}

\section{Discussão}

Modelos e estratégias usadas na educação em saúde

Esta categoria emergiu de quatro artigos ${ }^{7,12-14}$.

Os programas de combate a dengue apresentam um modelo de educação verticalizada, tradicional, centrada no emissor-canal-receptor. Este tipo de educação é caracterizado por um modelo centrado no emissor, o qual se apresenta como detentor do conhecimento e tem a missão de transmiti-lo para os demais. Esta prática não considera o contexto sociocultural dos envolvidos e objetiva a mudança de comportamentos e hábitos através da difusão do conhecimento ${ }^{7}$.

A prevenção da dengue apresenta-se intimamente ligada às práticas campanhistas/higienistas, voltadas para 0 combate ao vetor. Tais práticas cobram da população o fim dos criadouros domésticos, através da aplicação de larvicidas e retirada de pneus, garrafas e locais que mantenham água parada dos quintais. Há excesso de informações nesse modelo educativo, o que gera banalização do problema ${ }^{7}$.

Por ter cunho campanhista, estas informações, normalmente, circulam com maior intensidade durante os períodos mais favoráveis ao aparecimento da doença, o que caracteriza a educação sazonal, a qual objetiva atender aos surtos epidemiológicos ${ }^{15}$. A prática campanhista como, por exemplo, "Dia D da Dengue", apresenta ações temporárias, padronizadas e despreocupadas com as características sociais do local ${ }^{12}$.

Em um estudo realizado em Icaraí (CE), definiu-se as campanhas como estratégias não atrativas para a população, pois identificou que, além de não haver participação popular, a campanha observada em seu estudo concentrou-se nas partes centrais do município, sem se estender para os bairros onde há carência de infraestrutura, saneamento, educação em saúde, representando, assim, locais vulneráveis para a manutenção de criadouros, merecendo maior atenção ${ }^{12}$. 
As palestras também foram observadas como estratégia de educação em saúde, porém são práticas ainda restritas a médicos e enfermeiros, quando realizadas nas Unidades Básicas de Saúde (UBS). Já nos domicílios, o profissional responsável pela educação em saúde é o Agente Comunitário de Saúde (ACS). Isso pode refletir a ausência de articulação profissional, prática que não deveria existir, uma vez que a solução para problemas como dengue reside no interesse e união de todos ${ }^{12}$.

Outra forma de promover a educação em saúde é através da mídia, porém as informações, transmitidas pelas mídias de massa, apresentam caráter de denúncia, com conteúdos contraditórios ${ }^{7}$. Essa atitude gera confusão e alarmismo na população ao invés de promover a circulação de informações que contribuam para o controle da doença.

Buscando experiências inovadoras no processo de educação em saúde, estudos desenvolvidos na Bahia e no Rio de Janeiro relatam a experiência da promoção de educação em saúde usando formas alternativas como peça teatral, caminhada, sonorização e, principalmente, participação popular ${ }^{13,14}$.

Autores ${ }^{14}$ utilizaram caminhadas com sonorização como estratégia de educação adotada pelos alunos do projeto PET-Saúde da Universidade Estadual de Santa Cruz, Ilhéus-BA, com o objetivo de informar, de maneira lúdica, as formas de prevenção e combate da dengue. Durante a caminhada, houve a distribuição de panfletos informativos pelas ruas da cidade. Outra estratégia utilizada foi o uso de peça teatral nas escolas do bairro, a fim de tornar os alunos do ensino fundamental, multiplicadores de informações. A peça representava o cotidiano das pessoas, buscando promover a reflexão sobre as formas de enfrentamento da dengue.

Ao término do projeto dos autores citados ${ }^{14}$, houve reunião entre os participantes da pesquisa e os líderes comunitários, com o propósito de mostrar o resultado das ações desenvolvidas no município. Essa forma diferente de trabalhar a educação em saúde promove a participação popular, a construção de conhecimento coletivo e o cuidar integrado, através do trabalho desenvolvido com ensino-serviço-comunidade. Reforça-se a necessidade das práticas preventivas no cuidado em saúde e do desenvolvimento de ações voltadas à promoção, prevenção e assistência à saúde ${ }^{14}$.

Estudo $^{13}$ desenvolvido nas cidades de Itaboraí e Rio de Janeiro, no ano 2012, investigou a utilização da linguagem teatral para caracterizar concepções de agentes, envolvidos na prevenção da dengue. Através da interação entre Arte e Ciências da Saúde, os autores objetivaram criar ambientes favoráveis para a discussão dos determinantes da saúde. Os sujeitos envolvidos na referida pesquisa foram: professores, ACS e agentes de endemias, totalizando 104 participantes.

Os autores ${ }^{13}$ realizaram sete oficinas, as quais não tinham excessiva formalidade e apresentavam temas relacionados ao processo de educação e de promoção de saúde, estimulando a troca de conhecimento entre os envolvidos nas oficinas. Com isso, os autores desejavam ouvir o que a população sabia sobre o processo saúde-doença e sobre a dengue, possibilitando reflexão crítica de cada participante sobre suas contradições e necessidade de mudança.

Tais autores acreditam que a arte pode "descondicionar" comportamentos, educar e sensibilizar, sendo acessível à grande número de pessoas, possibilitando questionamento a respeito dos fenômenos da vida. Essa experiência foi considerada positiva e possível de ser usada para o entendimento da existência da dissociação entre conhecimento e prática ${ }^{13}$.

\section{Processo de educação em saúde: problemas e soluções}

Esta categoria emergiu de quatro artigos $7,12,13,15$.

As práticas de educação em saúde verticalizadas e centralizadas devem dar lugar a uma educação que promova a participação comunitária ${ }^{7}$. Além disso, deve haver mais consistência nas mensagens circulantes sobre a dengue, através da revisão dos conteúdos e do estabelecimento de uma comunicação clara e permanente entre serviço e população ${ }^{7}$.

Vista como problema, a linguagem, aliada à dificuldade dos profissionais em acreditar que a comunidade é capaz de encontrar soluções eficazes para o combate das doenças, como a dengue, torna o processo de educação em saúde difícil e menos eficaz ${ }^{12}$. A transmissão verticalizada faz com que os profissionais usem linguagens mais rebuscadas ou muito simplificadas, criando um distanciamento entre o emissor e receptor, o que promove 0 aprendizado através da imposição ${ }^{12}$.

A forma de abordagem do conteúdo e o caráter que o mesmo deve ter são fatores relevantes para a comunicação, visto que a informação deve ser suficiente para ampliar a participação comunitária nas políticas de saúde pública ${ }^{12,15}$. Existem problemas nas mensagens de combate a dengue na divulgação de informações como, por exemplo, interpretação errônea, ausência de significância por não ser apropriado ao contexto social, além de mostrarem-se repetitivas e com conteúdos exaustivamente trabalhados, o que confere banalização do tema e um descrédito da comunidade ${ }^{7}$.

Identifica-se a necessidade da participação popular junto às instituições, no planejamento das atividades que objetivam a prevenção e controle da dengue através da educação em saúde, fortalecendo o vínculo e criando uma abordagem que vise trabalhar a necessidade local. A valorização do conhecimento popular e das suas contribuições faz-se necessária na criação de intervenções participativas e eficazes ${ }^{12}$. 
Aspecto a ser destacado é a necessidade de educação continuada para os profissionais de saúde, objetivando capacitar a equipe a atuar de maneira aberta ao diálogo, valorizando, assim, os diferentes conhecimentos ${ }^{12}$. Para que a comunicação seja eficiente, é preciso que os sujeitos sejam reciprocamente comunicantes e que a comunicação seja vista como comum ao outro ${ }^{15}$.

Outro problema enfrentado na educação em saúde no combate a dengue é o caráter sazonal da circulação de informações, pois estas são intensificadas no verão, caracterizando uma comunicação voltada para conter a epidemia da doença, que é típica da estação. Isso gera problema no processo de educação em saúde, uma vez que não favorece a criação de um canal contínuo de comunicação e, ainda, sugere a ideia errônea que a dengue acontece somente nessa época do ano. Uma solução para tal problema é a criação de espaços de discussão permanentes nos serviços de saúde ${ }^{15}$.

A qualidade das informações também é vista como problema na promoção da educação em saúde, uma vez que os conteúdos informativos se restringem ao ciclo de vida do vetor, modos de transmissão, sintomatologia e prevenção. Essa educação é pautada no que é preconizado pelo Ministério da saúde, porém nem sempre corresponde às necessidades locais, o que pode não gerar mudança de hábitos, pois não atinge as questões culturais, crenças, valores e percepção de saúde-doença ${ }^{15}$.

$O$ descrédito da população em relação ao poder público é, também, encarado como um problema que influencia a educação em saúde no controle da dengue, posto que a população não confia nas intenções dos governantes, nem na promoção de saúde realizada pelos mesmos ${ }^{7,13}$.

\section{Considerações Finais}

Com esta revisão integrativa foi possível identificar a preocupação de diferentes profissionais da saúde no combate da dengue. Em contrapartida, evidenciou-se que há um quantitativo baixo de publicações brasileiras que associam 0 combate da dengue à educação em saúde, bem como a ausência de publicações em alguns anos.

Foi possível verificar, nos artigos lidos, a necessidade de mudanças nas estratégias de educação em saúde, tornando claro que a forma de educação tradicional, utilizada em algumas propostas de educação em saúde, não produz respostas positivas da população no controle da dengue. Como possíveis soluções para a promoção da adesão da população, experiências inovadoras de educação têm sido relatadas em alguns artigos, uma vez que apresentam perspectiva participativa da comunidade.

Outro aspecto que deve ser alterado é o caráter sazonal das estratégias de combate à dengue, substituindo-o por um trabalho contínuo de educação, uma vez que o objetivo não contempla somente a contenção de surtos epidêmicos, mas erradicar a doença do país, que hoje é tida como problema de saúde pública. Outra dificuldade evidenciada, nas publicações selecionadas, refere-se ao conteúdo das mensagens usadas nas estratégias de educação, que, normalmente, segue uma temática preconizada pelo Ministério da Saúde, sem considerar a necessidade local.

Ressalta-se, com este trabalho, a importância do desenvolvimento de práticas de educação em saúde em cenários diferentes como, por exemplo, escolas, praças, locais públicos, entre outros, tornando possível criar uma rede de multiplicadores de informações, que se apresenta com menos formalidade e mais interação entre facilitadores e população.

As atividades de educação em saúde, realizadas nas Unidades de Saúde, apresentam-se, na maioria das vezes, restritas ao uso de palestras ministradas pelos profissionais de nível superior, criando uma educação verticalizada e pouco atrativa.

Como mencionado anteriormente, há limitações e pontos a serem melhorados nas estratégias de educação em saúde utilizadas, entre as quais cita-se a falta de participação popular, a qual pode estar relacionada à resistência da população em aderir às campanhas, juntamente com a banalização do tema, que faz com que a doença seja vista como algo do cotidiano e não como um problema de saúde pública.

Diante disso, a dengue precisa ser entendida como problema de todos, cuja solução está na união de Estado, serviços, profissionais e população no enfrentamento da doença. Assim, a responsabilidade deve ser compartilhada e as soluções devem ser criadas a partir do trabalho conjunto entre Governo e sociedade.

O caráter sazonal das campanhas deve ser substituído por uma educação permanente, que valorize o conhecimento popular, e que promova intervenções considerando a realidade social e cultural das pessoas. 0 processo educativo deve acontecer de maneira horizontal, utilizando diferentes instrumentos promotores de educação como: rádio, TV, teatro, enfim, maneiras alternativas de educação que sensibilizem as pessoas e promovam interação entre emissor e receptor. A relação entre os profissionais de saúde e os líderes/representantes comunitários também é uma ferramenta importante nesse processo educativo, uma vez que essas pessoas podem difundir as informações adquiridas, promovendo educação comunitária. 
Acredita-se que problemas como a dengue são resolvidos com atividades coletivas e participação popular, pois a forma de educação que não considera os saberes populares não consegue sensibilizar as pessoas, tão pouco criar mudanças nas atitudes. Além disso, pesquisas que relacionem a dengue com a Educação em Saúde devem ser realizadas para promover a disseminação do conhecimento das estratégias para o combate/controle da dengue.

\section{Referências Bibliográficas}

1. Silva SJ, Mariano ZF, Scopel I. A dengue no Brasil e as políticas de combate ao aedes aegypti: da tentativa de erradicação ás políticas de controle. Hygeia. 2008;3(6):163-175.

2. Ministério da saúde (BR). Secretaria de Vigilância em Saúde. Departamento de Vigilância Epidemiológica. Doenças infecciosas e parasitárias: guia de bolso. 8a ed. rev. Brasília: Ministério da Saúde, 2010.

3. Torres EM. Dengue. Estud. av. 2008;22(64):33-52.

4. Ministério da saúde (BR). Fundação Nacional de Saúde. Dengue: aspectos epidemiológicos, diagnóstico e tratamento. Brasília: Fundação Nacional de Saúde, 2002.

5. Câmara FP, Theophilo RLG, Santos GT, Pereira SRFG, Câmara DCP, Matos RRC. Estudo retrospectivo (histórico) da dengue no Brasil: características regionais e dinâmicas. Rev. Soc. Bras. Med. Trop. 2007;40(2):192-196.

6. Tauil PL. Urbanização e ecologia do dengue. Cad. Saúde Pública. 2001;17 Suppl:99-102.

7. Rangel ML. Dengue: educação, comunicação e mobilização na perspectiva do controle - propostas inovadoras. Interface - Comunicação, Saúde, Educação. 2008;12(25):433-41.

8. Ministério da Saúde (BR). Caderno de Educação popular e saúde. Brasília: Ministério da Saúde: 2007.

9. Souza MT, Silva MD, Carvalho R. Revisão integrativa: o que é e como fazer. Einstein. 2010(8):102-6.

10. Mendes KDS, Silveira RCCP, Galvão CM. Revisão integrativa: método de pesquisa para a incorporação de evidências na saúde e na enfermagem. Texto \& contexto enferm. 2008;17(4):758-764.

11. Ursi ES. Prevenção de lesões de pele no perioperatório: revisão integrativa da literatura. Ribeirão Preto: [s.n], 2005. 130p. Dissertação (Mestrado) - Universidade de São Paulo, Escola de Enfermagem de Ribeirão Preto, 2005.

12. Sales FMS. Ações de educação em saúde para prevenção e controle da dengue: um estudo em Icaraí, Caucaia, Ceará. Ciênc. saúde coletiva. 2008,13(1):175-184.

13. Oliveira DF, Mendonça CCR, Meirelles RMS, Coutinho CMLM, Jorge CTCA, Luz MRMP. Construção de espaços de escuta, diagnóstico e análise coletiva de problemas de saúde pública com a linguagem teatral: 0 caso das oficinas de jogos teatrais sobre a dengue. Interface - Comunicação, Saúde, Educação. 2012;16(43):929-41.

14. Ferreira VS, Barreto RLM, Oliveira EK, Ferreira PRF, Santos LPS, Marques VEA, et al. PET-Saúde: uma Experiência Prática de Integração Ensino-serviço-comunidade. Rev. bras. educ. med. 2012;36(1) supl 2:147-51.

15. Silva LB, Soares SM, Fernandes MTO, Aquino Al. Comunicação sazonal sobre a dengue em grupos socioeducativos na atenção primária à saúde. Rev. saúde pública. 2011;45(6):1160-7.

\section{Ivanise Brito da Silva}

Endereço para correspondência - Rua: Cassilândia, n 384, Bairro: Várzea, CEP: 50740-370, Recife, PE, Brasil.

E-mail: ivanisebrito27@hotmail.com

Lattes: http://lattes.cnpq.br/0429493569364927

Danielli Gavião Mallmann - dani_mallmann@hotmail.com

Eliane Maria Ribeiro de Vasconcelos - emr.vasconcelos@gmail.com

Enviado em 13 de outubro de 2013. Aceito em 07 de julho de 2014. 
